\title{
EVALUASI PENGGUNAAN OBAT ANTIMUNTAH PADA PASIEN ANAK PENDERITA KANKER DI RUMAH SAKIT KANKER DHARMAIS JAKARTA PERIODE JUNI-JULI 2016
}

\author{
EVALUATION OF DRUG USE IN PATIENTS ANTIEMETIC CHILD \\ CANCER PATIENTS AT DHARMAIS CANCER HOSPITAL \\ JAKARTA PERIOD OF JUNE-JULY 2016 \\ Ridha Elvina $^{* 1)}$, Rahma Musyarofah ${ }^{1)}$, Risani Andalasia Putri ${ }^{2)}$ \\ ${ }^{1)}$ Fakultas Farmasi, Universitas Muhammadiyah Prof. Dr. Hamka , Jakarta \\ ${ }^{2)}$ Rumah Sakit Kanker Dharmais, Jakarta \\ *Penulis Korespondensi, e-mail : ridha.elvina@gmail.com
}

\begin{abstract}
ABSTRAK
Penyakit kanker rmerupakan salah satu penyebab kematian utama di seluruh dunia. Pada tahun 2012, kanker menjadi penyebab kematian sekitar 8,2 juta orang. Salah satu pengobatan kanker yaitu dengan cara kemoterapi. Efek samping yang paling besar dari pengobatan dengan cara kemoterapi adalah gangguan mual dan muntah. Penelitian ini bertujuan untuk mengevaluasi keberhasilan terapi pengobatan antimuntah didasarkan pada ketepatan pemilihan obat, dosis serta efek terapi yang dihasilkan. Metode yang digunakan bersifat deskriptif prospektif yaitu dengan memantau langsung penggunaan antimuntah pada pasien kanker anak paska kemoterapi di ruang rawat inap Rumah Sakit Kanker Dharmais Jakarta selama periode penelitian Juni-Juli 2016. Dari 35 pasien yang masuk kedalam kriteria inklusi, terlihat sebanyak $97,14 \%$ pasien mendapatkan obat antimuntah dengan dosis yang sesuai, dan sebanyak $100 \%$ pasien mendapatkan obat yang sesuai.
\end{abstract}

Kata kunci : kanker, mual dan muntah, kemoterapi

\section{ABSTRACT}

Cancer is one of the leading causes of death worldwide. In 2012, cancer causes the death of about 8.2 million people. One cancer treatment that is by chemotherapy. The side effects most from treatment with a chemotherapy are nausea and vomiting disorders. This study aimed to evaluate the success of therapeutic treatment based on the accuracy of antiemetic drug selection, dosage and therapeutic effects produced. The method used is deskriptif prospektif is to directly monitor the use of antiemetic in pediatric cancer patients after chemotherapy in inpatient Dharmais Cancer Hospital Jakarta during the study period from June to July 2016. Of the 35 patients who entered into the inclusion criteria, looks much as $97.14 \%$ of patients receive drugs to antiemetic with an appropriate dose, and as much as 100\% of patients get appropriate medication. 
Keywords: cancer,nausea and vomiting, chemotherapy

\section{PENDAHULUAN}

Penyakit kanker merupakan salah satu penyebab kematian utama di seluruh dunia. Pada tahun 2012, kanker menjadi penyebab kematian sekitar 8,2 juta orang (Kementerian Kesehatan RI, 2015). Kanker pada anak menjadi masalah bagi dunia karena kejadiannya terus mengalami peningkatan, terutama di negara-negara yang sedang berkembang (Chaudhry dan Siddiqui, 2012).

Berdasarkan data Riskesdas tahun 2013 didapatkan prevalensi penderita kanker di Indonesia sebesar 1,4\%, dengan prevalensi kanker tertinggi berada pada Provinsi DI Yogyakarta, yaitu sebesar 4,1\% kemudian diikuti oleh Jawa Tengah 2,1\%, Bali 2\%, Bengkulu dan Jakarta masing-masing 1,9\%. Sementara itu, di Indonesia terdapat sekitar 11.000 kasus kanker anak setiap tahunnya, dan terdapat sekitar 650 kasus kanker anak di Jakarta. Sebagian besar kanker anak muncul tanpa tanda dan gejala yang spesifik, sehingga dapat menyebabkan lambatnya kanker tersebut terdeteksi (Kementerian Kesehatan RI, 2015).

Salah satu pengobatan kanker yaitu dengan cara kemoterapi. Kemoterapi merupakan terapi untuk membunuh sel-sel kanker dengan obat-obat anti kanker yang disebut sitostatika. Obat anti kanker ini diberikan dalam bentuk tablet, suntikan, atau infus. Efek samping yang paling besar pada kemoterapi adalah gangguan mual dan muntah yang sangat bervariasidari yang ringan sampai kematian (Rahmah, 2009).

Dalam suatu penelitian yang dilakukan oleh Love et al., didapatkan persentase pasien yang mengalami efek samping dari kemoterapi yang dijalaninya yaitu mual $87 \%$, lelah $86 \%$, muntah $54 \%$, gangguan tidur $46 \%$, peningkatan berat badan $45 \%$, sariawan 44\%, kesemutan 42\%, gangguan pada mata 38\%, diare 37\%, konstipasi $19 \%$, kemerahan pada kulit 18\% dan penurunan berat badan 13\% (Faisel, 2012).

Mual dan muntah akibat kemoterapi (CINV) merupakan efek samping yang sering terjadi dan memberikan banyak kesulitan pada pasien kanker. Pasien kanker yang menjalani kemoterapi biasanya menempatkan mual dan muntah pada daftar efek samping kemoterapi yang paling diresahkan.Kurangnya kontrol muntah dapat 
mengganggu aktivitas fungsional dan kualitas hidup pasien, meningkatkan penggunaan sumber daya pelayanan kesehatan, dan mengurangi kepatuhan terhadap pengobatan (Hariyanto et al., 2015).

Pasien anak yang mendapatkan kesesuaian jenis obat anti muntah berdasarkan tingkatan emetogenik dari obat kemoterapi yang diberikan tahun 2012, sebesar 26,08\% untuk obat antimuntah tunggal intravena, 6,52\% untuk obat antimuntah per oral, dan 41,30\% untuk obat antimuntah kombinasi (Oktasari, 2015). Penatalaksanaan mual dan muntah yang tidak tepat dapat menghambat proses kemoterapi, menurunkan tingkat kesembuhan kanker, serta menimbulkan mual dan muntah tipe antisipatori yang berat (Tehuteru, 2007).Dengan pemberian antiemetik yang tepat dapat mencegah kejadian mual muntah pada 70-80\% pasien yang menjalani kemoterapi (Jordan et al., 2007).

\section{METODE PENELITIAN}

Jenis Penelitian

Penelitian ini termasuk jenis penelitian deskriptif dengan teknik pengambilan data secara prospektif.

Alat dan Bahan

Bahan yang digunakan adalah catatan medik pasien kanker yang menjalani rawat inap di Instalasi Rawat Inap Rumah Sakit Kanker Dharmais Jakarta Periode Juni-Juli 2016. Alat yang digunakan adalah pedoman National Comprehensive Cancer Network (NCCN) 2012 untuk melihat ketepatan pemilihan obat antimuntah dan Drug Information Handbook (DIH) 2015 untuk melihat ketepatan dosis.

\section{Subyek Penelitian}

Pasien anak yang didiagnosa kanker dan menjalani rawat inap di Instalasi rawat inap Rumah Sakit Kanker Dharmais Jakarta yang mengalami mual dan muntah selama periode Juni-Juli 2016.

Pengumpulan Data

Data yang diambil menggunakan metode Total Sampling dan didapatkan sebanyak 35 pasien. Data yang diambil meliputi: jenis kanker, stadium kanker, jenis 
antimuntah, dosis, waktu pemberian, lama pemberian, obat yang digunakan serta efek terapi yang dihasilkan.

Analisis Data

Data-data yang diperoleh dari tahap sebelumnya ditabulasikan dalam formulir penelitian, selanjutnya dianalisis secara akumulatif dan disajikan dalam bentuk tabel distribusi dan frekuensi/grafik, yaitu:

a. Menganalisis kasus kanker di Rumah Sakit Kanker Dharmais selama Juni sampai Juli 2016.

b. Mengidentifikasi karakteristik subyek penelitian.

c. Menganalisis jenis kanker, stadium kanker, dan jenis obat antimuntah pasca kemoterapi pada pasien kanker anak.

d. Menganalisis ketepatan obat, tepat dosis,dan waktu pemberian obat antimuntah.

\section{HASIL DAN PEMBAHASAN}

Karakteristik pasien kanker

Tabel I menunjukan karakteristik pasien anak penderita kanker di ruang rawat inap rumah sakit Kanker Dharmais Jakarta periode Juni-Juli 2016, yaitu sebanyak 21pasien perempuan dan sebanyak 14 pasien laki-laki. Usia dikelompokan menjadi 4 kelompok berdasarkan Kementrian Kesehatan tahun 2013.

Tabel I. Distribusi pasien apa di mana berdasarkan usia dan jenis kelamin

\begin{tabular}{lcc}
\hline \multicolumn{1}{c}{ Usia } & Laki-Laki & $\begin{array}{c}\text { Jenis Kelamin } \\
\text { Perempuan }\end{array}$ \\
\hline $0-4$ tahun & 3 & 5 \\
5-9 tahun & 2 & 3 \\
10-14 tahun & 4 & 6 \\
15-19 tahun & 5 & 7 \\
$\quad$ Total & 14 & 21 \\
\hline
\end{tabular}

Tabel II menunjukkan bahwa dari 35 pasien anak penderita kanker yang diambil datanya secara prospektif terlihat sebanyak $40 \%$ pasien menderita Leukemia Limfositik Akut. Tingginya angka kejadian kanker leukemia limfositik akut ini sama 
dengan laporan Association for Clinical Cytogenetics tahun 2011 yang menyatakan bahwa leukemia limfositik akut merupakan kanker dengan angka kejadian tinggi pada anak sebanyak $75 \%$ dari semua kanker yang menyerang anak.

Jenis dan stadium kanker

Tabel II. Distribusi pasien berdasarkan jenis dan stadium kanker

\begin{tabular}{lcc}
\hline \multicolumn{1}{c}{ Jenis Kanker } & Jumlah Pasien & Persentase \\
\hline Leukemia Limfositik Akut & 14 & $40 \%$ \\
Kanker Nasofaring & 7 & $20 \%$ \\
Limfoma Malignant non & 2 & $5,71 \%$ \\
Hodgkin & & \\
Tumor yolksack & 3 & $8,57 \%$ \\
Neuroblastoma & 2 & $5,71 \%$ \\
Osteosarkoma & 1 & $2,86 \%$ \\
Leukemia Mielositik Akut & 1 & $2,86 \%$ \\
Limfoma Burkit & 1 & $2,86 \%$ \\
Longerhans & 3 & $8,57 \%$ \\
Limfoma sel T & 1 & $2,86 \%$ \\
Total & 35 & 100 \\
\hline
\end{tabular}

Leukemia merupakan penyakit kanker yang terbanyak pada anak-anak.Leukemia limfoblastik akut (LLA) menempati peringkat paling atas diantara penyakit kanker anak yang dirawat di Departemen Ilmu Kesehatan Anak FKUI/RSCM dengan jumlah pasien baru 60-70 pasien per tahunnya (Sari et al,. 2010).

Distribusi jumlah pasien anak yang menderita kanker di Rumah Sakit Kanker Dharmais pada bulan Juni sampai Juli 2016 berdasarkan stadium kanker dapat dilihat pada Tabel III. Dari data tersebut, jumlah pasien paling banyak terjadi pada Kanker leukemia limfositik akut stadium III.Stadium III dapat dikategorikan stadium lanjut. Pada stadium III memang lebih sering dirawat di rumah sakit dikarenakan kebanyakan pasien tidak mengetahui adanya pertumbuhan sel kanker pada stadium dini. 
Stadium sendiri diartikan sebagai keputusan klinis yang berkaitan dengan ukuran tumor, derajat invasi lokal yang telah terjadi, dan derajat penyebarannya ke tempattempat yang jauh pada individu tertentu (Corwin, 2009).

Tabel III. Distribusi pasien berdasarkan stadium kanker Di Rumah Sakit Kanker Dharmais Jakarta Periode Juni-Juli 2016

\begin{tabular}{lccc}
\hline \multicolumn{1}{c}{ Jenis Kanker } & $\begin{array}{c}\text { Stadium } \\
\text { kanker }\end{array}$ & Jumlah & Persentase \\
\hline Leukemia Limfositik Akut & II & 5 & $14,28 \%$ \\
& III & 7 & $20 \%$ \\
Kanker Nasofaring & IV & 2 & $5,71 \%$ \\
& II & 1 & $2,86 \%$ \\
Limfoma Malignant non & IV & 5 & $14,28 \%$ \\
Hodgkin & III & 1 & $2,86 \%$ \\
& IV & 1 & \\
Tumor yolksack & & & $2,86 \%$ \\
Neuroblastoma & II & 1 & $2,86 \%$ \\
Osteosarkoma & III & 2 & \\
Leukemia Mielositik Akut & II & 2 & $2,86 \%$ \\
Limfoma Burkit & IV & 1 & $5,71 \%$ \\
Longerhans & III & 1 & $2,71 \%$ \\
Limfoma sel T & II & 1 & $2,86 \%$ \\
Total & II & 3 & $2,86 \%$ \\
\end{tabular}

Siklus kemoterapi yang dijalani pasien

Seluruh pasien anak yang menjalani pengobatan kemoterapi sesuai dengan diagnosa penyakit yang ditetapkan, dalam berbagai macam siklus kemoterapi.Obat-obat kemoterapi diberikan selama beberapa minggu dan dijeda dengan istirahat satu minggu untuk memberikan kesempatan bagi jaringan normal untuk tumbuh kembali. Seluruh pasien yang menjalani kemoterapi dikelompokkan berdasarkan siklus kemoterapi yang mereka jalani (Oktasari, 2015). 
Tabel IV. Distribusi siklus kemoterapi yang dijalani pasien

\begin{tabular}{lccc}
\hline \multicolumn{1}{c}{ Diagnosa Penyakit } & $\begin{array}{c}\text { Siklus } \\
\text { Kemoterapi } \\
\text { (Weekly) }\end{array}$ & Jumlah & $\begin{array}{c}\text { Persentase } \\
(\%)\end{array}$ \\
\hline & 0 & 4 & $11,42 \%$ \\
& 1 & 1 & $2,86 \%$ \\
Leukemia Limfositik Akut & 2 & 3 & $8,57 \%$ \\
& 3 & 2 & $5,71 \%$ \\
& 4 & 1 & $2,86 \%$ \\
Kanker Nasofaring & 5 & 1 & $2,86 \%$ \\
Limfoma Malignant non & 6 & 2 & $5,71 \%$ \\
Hodgkin & 1 & 2 & \\
Tumor yolksack & 3 & 2 & $5,71 \%$ \\
Neuroblastoma & 6 & 3 & $8,71 \%$ \\
Osteosarkoma & 2 & 1 & $2,86 \%$ \\
Leukemia Mielositik Akut & 6 & 1 & $2,86 \%$ \\
Limfoma Burkit & 2 & 1 & $2,86 \%$ \\
& 6 & 2 & $5,71 \%$ \\
Longerhans & 2 & 2 & $5,71 \%$ \\
& 2 & 1 & $2,86 \%$ \\
Limfoma sel T & 3 & 1 & $2,86 \%$ \\
& 1 & 1 & $2,86 \%$ \\
& 2 & 1 & $2,86 \%$ \\
& 6 & 1 & $2,86 \%$ \\
& 2 & 1 & $2,86 \%$ \\
& & 1 & $2,86 \%$ \\
& & & \\
\hline
\end{tabular}

Penggunaan obat kemoterapi

Pada Tabel V dapat dilihat pasien yang mendapatkan obat kemoterapi ringan dengan obat mercaptopurine (6-MP) sebanyak 15 pasien $(42,86 \%)$, sedangkan pada pasien yang mendapatkan obat kemoterapi sedang dengan obat leucovorinter dapat 12 pasien $(34,28 \%)$ dan obat vincristine terdapat 8 pasien $(22,86 \%)$. 
Tabel V. Obat kemoterapi berdasarkan tingkatan agen kemoterapi yang diberikan pada pasien kanker di RS Kanker Dharmais periode Juni-Juli 2016

\begin{tabular}{lccc}
\hline \multicolumn{1}{c}{ Obat yang Digunakan } & $\begin{array}{c}\text { Intensitas Mual dan } \\
\text { Muntah }\end{array}$ & Jumlah Kasus & Persentase \\
\hline 6-MP (Mercaptopurine) & Ringan & 15 & $42.86 \%$ \\
Leucovorin & Sedang & 12 & $34.28 \%$ \\
Vincristine & Sedang & 8 & $22.86 \%$ \\
Total & & 35 & 100 \\
\hline
\end{tabular}

Antimuntah yang digunakan

Berdasarkan Tabel VI dapat diketahui antimuntah tunggal yang paling sering digunakan adalah ondansetron. Menurut panduan $N C C N$, ondansetron adalah golongan dari antagonis serotonin (5-HT 3) untuk penggunaan antiemetik sebagai obat mual/ muntah yang tidak terkait dengan radiasi, untuk rejimen obat multi, pilih terapi antiemetik berdasarkan obat dengan risiko muntah tertinggi. Seluruh pasien yang menerima obat antimuntah sebelum, selama dan sesudah kemoterapi telah mendapatkan dosis yang sesuai dengan standar NCCN (National Comprehensive Cancer Network) Antiemesis Anak 2012. Menurut data ini pasien menerima kesesuaian dosis hampir $100 \%$ dan kesesuaian obat sebesar $100 \%$.

Pada evaluasi pemilihan obat didapatkan sebanyak $100 \%$ obat sesuai acuan yang digunakan, namun untuk aturan pemakaian obat antimuntah ada satu kasus dimana pasien yang tidak patuh, yaitu penghentian penggunaan obat sebelum seluruh rangkaian pengobatan selesai, baik karena pasien merasa lebih baik ataupun karena mengalami beberapa efek merugikan yang tidak diharapkan. Sehingga dalam hal ini farmasis/petugas medis lainnya perlu memperhatikan pola kepatuhan pasien untuk menghasilkan efek terapeutik yang diinginkan (Oktasari, 2015).

Penggunaan obat antimuntah tunggal dengan obat antimuntah kombinasi bertujuan untuk melihat perbandingan obat manakah yang memiliki kemampuan lebih baik dalam mencegah muntah. Obat antimuntah yang mempunyai kemampuan lebih baik untuk pencegahan mual dan muntah adalah obat antimuntah kombinasi golongan antagonis serotonin dan kortikosteroid (ondansetron+dexamethasone). 
Tabel VI. Obat antimuntah pasien kanker anak di RS Kanker Dharmais periode JuniJuli 2016

\begin{tabular}{clcccc}
\hline \multirow{2}{*}{ Kategori } & \multicolumn{1}{c}{ Jenis Obat Antimuntah } & $\begin{array}{c}\text { Jumlah } \\
\text { Kasus }\end{array}$ & $\begin{array}{c}\text { Tepat } \\
\text { Tunggal }\end{array}$ & $\begin{array}{c}\text { Tidak } \\
\text { Tepat }\end{array}$ & Persentase \\
\hline \multirow{5}{*}{ Ondansetron (P.O) } & 1 & $\sqrt{ }$ & $31,43 \%$ \\
& Ondansetron (IV) & 6 & $\sqrt{ }$ & $17,14 \%$ \\
& Dexamethasone (P.O) & 3 & $\sqrt{ }$ & $8,57 \%$ \\
& Ondansetron(P.O)+Dexamethasone & 3 & $\sqrt{ }$ & $8,57 \%$ \\
& (P.O) & & & & $14,29 \%$ \\
& Ondansetron(IV)+ & 5 & $\sqrt{ }$ & $11,43 \%$ \\
& Dexamethasone(P.O) & & & $5,71 \%$ \\
Tombinasi & Ondansetron(P.O) & 4 & $\sqrt{ }$ & $2,86 \%$ \\
& +Dexamethasone(IV) & & $\sqrt{ }$ & $100 \%$ \\
\hline
\end{tabular}

Evaluasi ketepatan obat dan dosis antimuntah

Pada Tabel VII terlihat sebanyak $100 \%$ pasien mendapatkan obat antimuntah dengan dosis yang sesuai literature Drug Information Handbook (DIH)2015 dan National Comprehensive Cancer Network (NCCN) 2012. Dalam penelitian kali ini terlihat lebih banyak pasien yang mendapatkan obat antimuntah kombinasi dibandingkan obat antimuntah tunggal. Untuk aturan pemakaian obat antimuntah terdapat satu kasus dimana pasien yang tidak patuh, yaitu penghentian penggunaan obat sebelum seluruh rangkaian pengobatan selesai, baik karena pasien merasa lebih baik ataupun karena mengalami beberapa efek merugikan yang tidak diharapkan. Sehingga dalam hal ini farmasis/petugas medis lainnya perlu memperhatikan pola kepatuhan pasien untuk menghasilkan efek terapeutik yang diinginkan (Oktasari, 2015). 
Tabel VII. Evaluasi ketepatan antimuntah berdasarkan ketepatan obat dan dosis Pada Pasien Kanker Anak di Rs Kanker Dharmais Periode Juni-Juli 2016 (Sumber Data Rekam Medik)

\begin{tabular}{ccccccc}
\hline Parameter & \multicolumn{2}{c}{ Tepat } & \multicolumn{2}{c}{ Tidak tepat } & \multicolumn{2}{c}{ Total } \\
& Jumlah & Persentase & Jumlah & Persentase & Jumlah & Persentase \\
\hline $\begin{array}{c}\text { Ketepatan } \\
\begin{array}{c}\text { Obat } \\
\text { Ketepatan } \\
\text { Dosis }\end{array}\end{array}$ & 35 & $100 \%$ & 0 & - & 35 & $100 \%$ \\
\hline
\end{tabular}

Golongan antagonis serotonin dapat diberikan sebagai agen tunggal pada level muntah sedang. Untuk risiko muntah tinggi dapat diberikan aprepitant + deksametason, atau serotonin antagonist + dexametason ataupun metoklopramid + deksametason. Pada tipe muntah akut, untuk regimen kemoterapi yang biasanya menimbulkan risiko muntah sedang sampai tinggi dianjurkan untuk penggunaan antiemetik kombinasi. Antiemetik kombinasi antagonis serotonin + deksametason + aprepitant untuk risiko muntah tinggi, serta antagonis serotonin dan deksametason untuk risiko sedang. Untuk regimen kemoterapi dengan risiko muntah rendah dapat digunakan antiemetik tunggal seperti kortikosteroid atau antagonis serotonin ataupun tidak diperlukan antiemetik bila risiko muntah sangat rendah (Rahmah, 2009). Obat antimuntah yang memiliki kemampuan lebih baik untuk pencegahan mual dan muntah karena induksi dari obat kemoterapi yang diberikan yaitu obat antimuntah kombinasi antagonis serotonin + kortikosteroid (ondansetron + dexamethasone) (Oktasari, 2015).

Untuk aturan pemakaian obat ada pasien yang tidak mendapatkan obat antimuntah sebelum kemoterapi dengan alasan ketepatan jadwal kemoterapi dan lamanya waktu pasien di rawat inap. Sedangkan pada frekuensi/ lama pemberian obat antimuntah terdapat beberapa siklus kemoterapi yang mendapatkan obat antimuntah hanya 1 hari setelah kemoterapi. Waktu pemberian obat antimuntah disesuaikan dengan kesiapan pasien dalam menerima obat antimuntah baik secara parenteral maupun oral, serta ketersediaan obat antimuntah pada depo farmasi dengan keseragaman waktu sesuai instruksi pemberian (Oktasari, 2015). 
Dalam hal ini menunjukkan bahwa masih adanya kekurangan koordinasi dengan petugas medis, serta kurangnya informasi pada pasien tentang pentingnya pemberian obat antimuntah sebelum, selama, dan sesudah kemoterapi, pemantauan lama pemberian obat antimuntah dan waktu pemberian obat antimuntah.Serta adanya faktor-faktor lain yang mempengaruhi selama menjalani pengobatan.

\section{KESIMPULAN}

Dari hasil evaluasi penggunaan obat antimuntah pada pasien anak penderita kanker di Rumah Sakit Kanker Dharmais yang dirawat inap selama bulan Juni-Juli 2016, didapatkan kesimpulan sebagai berikut : Ketepatan obat pada penelitian ini $100 \%$ berdasarkan panduan National Comprehensive Cancer Network (NCCN) 2012, Ketepatan dosis pada penelitian ini $100 \%$ menurut panduan Drug Information Handbook (DIH), Untuk regimen kemoterapi dengan risiko muntah rendah dapat digunakan antiemetik tunggal seperti kortikosteroid atau antagonis serotonin dan obat antimuntah yang memiliki kemampuan lebih baik untuk pencegahan mual dan muntah karena induksi dari obat kemoterapi yang diberikan yaitu obat antimuntah kombinasi antagonis serotonin + kortikosteroid (ondansetron + dexamethasone).

\section{DAFTAR PUSTAKA}

Brenner David. J, D. Carl, Elliston, Hall Eric, Berdon E, Walter, 2001, Estimated Risks of Radiation-Induced Fatal Cancer from Pediatric CT. Diagnostic Imaging and Related Sciences. American Journal of Roentgenology.176 (2).

Corwin EJ. 2009. Buku Saku Patofisiologi (Edisi Revisi 3), Terjemahan: Nike Budhi Subyekti.EGC. Jakarta: 66-95.

Faisel CTW, 2012, Gambaran Efek Samping Kemoterapi Berbasis Antrasiklin Pada Pasien Kanker Payudara Di RSUD Dokter Soedarso Pontianak, Naskah Publikasi. Universitas Tanjungpura, Pontianak.

Gruenberg SM. DuganM. GrallaRJ, 2004., Management ofNausea and Vomiting.

Gunawan GS., 2009., Farmakologi dan Terapi Edisi 5., Gaya baru, Jakarta: 735-736 
Gusnita Endah. 2006. Kajian Penggunaan Antiemetik Yang Menyertai Pemberian Kemoterapi Taksan Pada Pasien Kanker Payudara Di Ruang Rawat Singkat RS Kanker Dharmais Pada Tahun 2005.Skripsi. Universitas Indonesia, Jakarta: 15-18.

Hariyanto BEP, Mantik MFJ, Wahani Audrey., 2015., Kejadian Muntah Pada Penderita Kanker Yang Menjalani Pengobatan Kemoterapi Di RSUP Prof. Dr. R. D. Kandou Manado. Jurnal e-Clinic.

Hayati Happy, 2009., Pengaruh Distraksi Oleh Keluarga Terhadap Mual-Muntah Akut Akibat Kemoterapi Pada Anak Usia Prasekolah Di RSUPN Cipto Mangunkusumo Jakarta., Tesis, Universitas Indonesia, Depok.

Hesketh PJ, 2008., Chemotherapy-Induced Nausea and Vomiting. NEJM. International Journal.

Rahmah DS., 2009., Evaluasi Penggunaan Obat Antimuntah pada Pasien Retinoblastoma Anak yang Menjalani Kemoterapi di Rumah Sakit Kanker "Dharmais". Indonesian Journal of Cancer.3(1): 1

Oktasari Diah, 2015., Evaluasi Penggunaan Obat Antimuntah Pasien Leukemia Anak yang Menjalani Kemoterapi Di Rumah Sakit Kanker Dharmais Periode MeiJuli 2012, Skripsi, Uhamka, Jakarta: 18-19.

Pappas SR, 1999.The Effect of Preoperative Dexamethasone on the Immediate and Delayed Postoperatine Morbidity in Children Undergoing Tonsilektomy. NCBI Journal.87(1): 57-61.

Sari TT, Windiastuti, Cempako, Devaera., 2010, Prognosis Leukemia Limfoblastik Akut pada Anak Obes, Jurnal.12.(1). 